\title{
НЕСКУЧНЫЙ САД БОРИСА ПАСТЕРНАКА: МЕЖДУ ДВУМЯ ПОЭТИЧЕСКИМИ КНИГАМИ (ПОЭЗИЯ И ЕЕ „ОПРЕДЕЛЕНИЯ”)
}

\author{
BORIS PASTERNAK'S NESKUCHNY SAD: \\ BETWEEN TWO POETIC BOOKS \\ (POETRY AND ITS “DEFINITIONS”)
}

\author{
КСЕНИЯ АБРАМОВА
}

\begin{abstract}
Aвstract. The article analyzes Boris Pasternak's Poeziya (Poetry) from the cycle Neskuchny Sad. The cycle is the kind of a link between two poetic books of Boris Pasternak: Sestra moya - zhizn' (My sister - Life) and Temy i variatsii (Themes and variations). We dwell in detail on the comparison of this text with the poem Opredeleniye poezii (Definition of poetry) from the book Sestra moya - zhizn'. We are mainly interested in the asemantic level of texts - their sound and rhythmic organization. The analyzed structure allows us to trace the dynamics of the images and the changes that took place in the poetic style of Boris Pasternak in the 1920s.
\end{abstract}

Keywords: Boris Pasternak, book of verses, asemantic level, sound organization of the text, rhythmic organization of the text

Ксения Абрамова, Новосибирский государственный педагогический университет, Новосибирск - Россия, a-ks@yandex.ru

ORCID ID: 0000-0003-1341-6083

В начале 1923 года в Берлине вышла четвертая книга стихов Бориса Пастернака Темы и вариации. Известен отзыв самого поэта о книге: он назвал ее „высевками и опилками” [Пастернак 1993: 348], так как в нее были включены стихотворения, не вошедшие в книгу Сестра моя - жизнь, принесшую ее автору широкую известность [см. Сергеева-Клятис 2013; Пастернак 2012 I]. Вышедшая вслед за ней книга стихов Темы и вариащии, в которой присутствовали, хотя часто преображенными, темы и мотивы Сестры моей жизни, как будто побуждала читателя к их сопоставлению. Отметим, что четвертую книгу стихов Борис Пастернак хотел назвать Оборотная сторона медали, имея в виду то, что в ней отображена „подоплека, изнанка" предшествующей книги. Кроме того, сближение поэтических сборников подчеркивается еще и тем, что стихотворные книги были выпущены автором под одной обложкой в 1927 году, в сборнике Две книги, где перед их названиями сделаны заголовки Первая книга 
и Вторая книга. В статье стихотворения цитируются по этому изданию [Пастернак 1927].

Взаимосвязь книг прослеживается не только в истории их создания и публикации, но и на семантическом уровне. В книге Сестра моя - жизнь отразились отношения Бориса Пастернака с Еленой Виноград, их прогулки по Москве, поездки поэта на поезде в Романовку и Балашов [Пастернак 2003: 453]. По замечанию Вадима Баевского и Ирины Романовой, эта книга может быть „осознана как своеобразный роман в стихах, состоящий из одних лирических отступлений" [Баевский, Романова 2008: 31]. Книга Темы и вариации как будто продолжает любовную линию, начатую в предыдущей книге, переосмысляет ее. Наиболее ярко это проявляется в циклах Болезнь и Разры८, ставшими, по словам комментаторов Евгения Борисовича Пастернака и Евгении Владимировны Пастернак, „как бы завершением или эпилогом романа Сестры моей жизни" [Пастернак 2003: 478]. В этих циклах как будто обыгрывается, заново переживается расставание лирического героя с возлюбленной, но уже гораздо эмоциональнее и экспрессивнее [см. Абрамова 2011; Абрамова 2012].

Мы остановимся на цикле Нескучный сад, чтобы показать, как в нем проявляются темы, мотивы и черты поэтики, характерные для книги Сeстра моя - жизнь, и как они изменяются и преображаются в книге Темы и вариации. Тема взаимосвязи и сопоставления этих поэтических книг Бориса Пастернака практически не рассматривалась литературоведами, хотя в некоторых работах упоминается о сходствах и отличиях двух книг стихов Бориса Пастернака. Например, Владимир Альфонсов писал:

Стихи, вошедшие в книгу Темы и вариации (1923), примыкают к Сестре, а некоторые и писались одновременно с Сестрой. Но составлены книги таким образом, что Темы и вариации являют новый этап, отчасти даже полемичный по отношению к Сестре. Темы и вариации напряженнее и драматичнее уже тем, что включают ситуации, отпавшие от нормы, это закреплено в самих названиях отдельных циклов - Болезнь, Разрыв. И революционная эпоха здесь больше почувствована в сломах, катаклизмах, связь поэта с нею - объективно сложнее, противоречивее, чем в Сестре [Альфонсов 1990: 113].

Отметим, что существует лишь одно исследование, в котором подробно анализируются преломление тем и мотивов Сестры моей жизни в первых шести стихотворениях цикла Нескучный сад [см. Мальцева 2015].

В первую очередь нас интересует один текст из цикла Нескучный сад: стихотворение Поэзия, не входящее ни в один из микроциклов Нескучного сада и располагающееся между микроциклом Сон $b$ летнюю ночъ и микроциклом Два письма. Оно было написано одним из последних в книге Темы и вариации, в 1922 году (вместе с Я вишу на пере у твориа..., Пей и пиши, непрерывным патрулем...), то есть его нельзя отнести к „высевкам 
и опилкам", оставшимся от книги Сестра моя жизнь, но в нем, на наш взгляд, можно проследить те изменения, которые происходили в поэтическом стиле Бориса Пастернака в 1920-х годах.

Стихотворение Поэзия посвящено темам творчества, вдохновения, экстатического момента созидания, которые пронизывают многие произведения Пастернака [см. Горелик 2011]:

\section{Поэзия, я буду клясться}

Тобой, и кончу, прохрипев:

Ты не осанка сладкогласца,

Ты - лето с местом в третьем классе,

Ты - пригород, а не припев.

Здесь также ярко отражается принцип ранней поэтики Пастернака, который Самсон Бройтман называл „субъектным и образным неосинкретизмом" и который проявлялся в „соответствии” и рядоположении на одной плоскости разных начал [Бройтман 2006: 276]. Отметим, что подобным образом стиль Пастернака характеризовался уже в 1920-х годах - в статьях, посвященных книге Сестра моя - жизнъ. Юрий Тынянов говорил о „рождении стиха среди вещей” [Тынянов 1977: 183], а Валерий Брюсов о том, что „все на равных правах входит в стихи Пастернака, располагаясь как бы на одной плоскости" [Брюсов 1922]. В рассматриваемом тексте в своеобразной попытке дать „определение” поэзии как будто соединяются абсолютно разноплановые предметы и понятия: „лето с местом в третьем классе”, „„пригород”, , душная как май Ямская", „Шевардина ночной редут". В стихотворении не просто отражается обращение поэта к вдохновению и творчеству, не только предпринимается попытка „определить”, назвать поэтическую силу, но и содержится своеобразное стремление воссоздать мироздание, организующим началом которого становится поэзия.

Стихотворение Поэзия примыкает к одному из „излюбленных Пастернаком жанров поэтического дискурса - стихам про «Ты»... в форме «Ты [есть] то-то и то-то»" [Жолковский 2014: 85]. Но также оно и по своему содержанию, и по своему строению отсылает к стихотворению Определение поэзии из книги Сестра моя - жизнъ, которое относится ко второму жанру, отмеченному Александром Жолковским: к „стихам про «Это», дающим определение абстрактным сущностям в виде «Это [есть] то-то и то-то»" [Жолковский 2014: 85]:

Это - круто налившийся свист,

Это - щелканье сдавленных льдинок,

Это - ночь, леденящая лист,

Это - Двух соловьев поединок. 
Это - сладкий заглохший горох,

Это - слезы вселенной в лопатках,

Это - с пультов и флейт - Figaro

Низвергается градом на грядку.

Соотносится с ними и раннее стихотворение Лесное, опубликованное в первой книге стихов Бориса Пастернака Близнец $b$ myчах. Оно строится на конструкции „Я [есть] то-то и то-то": „Я - уст безвестных разговор"; „Я - речь безгласного их края, / Я - их лесного слова дар"; „Я - уст безвестных разговор, / Я - столп дремучих диалектов".

В рассматриваемых текстах делается своеобразная попытка передать то, чем является поэзия. Несмотря на схожесть и ассоциативность конструкций „Ты - то-то и то-то” и „Это - то-то и то-то” и на то, что в стихотворениях Пастернак дает определение одному явлению - поэзии, тексты различаются семантическими коннотациями и внутренней динамикой образов. Конечно же, любой поэтический текст уникален, но, на наш взгляд, из-за перечисленных нами черт, объединяющих эти стихотворения, можно увидеть изменение поэтики произведений Бориса Пастернака в 1920-е годы.

В стихотворении Определение поэзии текст предельно назывной, в нем возникает всего несколько глаголов, все в третьей и четвертой строфах, и почти все они - инфинитивы:

Bсе, что ночи так важно сыскать

На глубоких купаленных доньях,

И звезду донести до садка

На трепещущих мокрых ладонях.

Площе досок в воде - духота.

Небосвод завалился ольхою.

Этим звездам к лицу б хохотать,

Ан вселенная - место глухое.

Использование инфинитивов, по замечанию Жолковского, придает „высокую степень риторичности конструкции” [Жолковский 2011: 210], которая поддерживается анафорическими повторами „это” и, отметим также, синтаксически параллельным построением второй и четвертой строк в приведенной строфе: „На глубоких купаленных доньях” и „На трепещущих мокрых ладонях". Параллелизм в указанных строках усиливает ощущение повторяющейся, постоянно возвращающейся мысли, рассуждения о том, чем является поэзия.

В Определении поэзии сочетаются, с одной стороны, именной стиль, который как будто показывает картину существующего сейчас, в настоящем, и, с другой стороны, инфинитивное письмо, в котором предстает 
„виртуальная реальность, которую поэт держит перед мысленным взором" [Жолковский 2011: 211].

В стихотворении Поэзия на первый план выдвигается действие, хотя в первой строфе, после первых двух строк с глагольными конструкциями „буду клясться” и „кончу, прохрипев” начинается серия строк, схожая по строению с теми, которые были в Определении поэзии из Сестры моей жизни:

Ты не осанка сладкогласца,

Ты - лето с местом в третьем классе,

Ты - пригород а не припев.

Но в этих перечислениях риторичность как будто отодвигается на задний план, здесь поэт уже не отвлеченно рассуждает о том, что есть поэзия, а обращается к ней. Аналогия строится на отрицании и антитезах, что придает ей дополнительный динамический оттенок и экспрессивную окраску.

В стихотворении Определение поэзии многие сравнения насыщены звуковыми ассоциациями: „круто налившийся свист”, „щелканье сдавленных льдинок”, „Двух соловьев поединок”, „с пультов и флейт - Figaro”, а в Поэзии Нескучного сада появляются парадоксальные противопоставления, в которых отрицаются как раз образы, связанные со звуком: „Ты не осанка сладкогласца”, „Ты - пригород, а не припев” и „Предместье, а не перепев". По мнению Баевского, здесь отражается антиромантическая и антисимволистская направленность этого стихотворения: исследователь отмечает, что выражение „сладкий глас”, „сладкий голос” характерно для поэзии начала XIX века, а в стихотворении Поэзия, если толковать его в духе Михаила Гаспарова и Ирины Подгаецкой [см. Гаспаров, Поливанов 2005; Гаспаров, Подгаецкая 2008], „сладкогласец” предстает как фигура, над которой иронизирует автор, которому поэзия не может принадлежать. Поэзия же оказывается чем-то неповторимым, свежим, новым („не припев” и „не перепев”, а „пригород, предместье”) [Баевский 2011: 533].

Отметим, что иронический подтекст, который появляется в Поэзии с помощью указанных отрицаний, может присутствовать и в Определении поэзии, только он создается уже другими средствами. Борис Гаспаров пишет:

Содержание этих псевдо-философских тезисов таково, что заставляет заподозрить насмешку. Тем более, что между постулируемыми „определениями” так мало общего (по крайней мере на поверхности), что их объединение в некое подобие матрицы только усиливает пародийный эффект [Гаспаров 2013: 208]. 
С нашей точки зрения, и в том, и в другом тексте иронические ноты в перечислениях присутствуют, но нам важнее подчеркнуть то, что в Определении поэзии звуковые образы преображаются, приводят к тому, что Вселенная обращается в „место глухое” (и в смысле отсутствия возможности быть услышанным), в то время как в стихотворении Поэзия отрицание связи со „звуком" выливается в беспрерывное звучание всего мира.

Это происходит и на асемантическом уровне стихотворения, который мы анализируем, опираясь на исследования Юрия Чумакова [см. Чумаков 2017], что мы попытаемся показать далее. Отметим, что звуковой уровень стихотворения Определение поэзии, как и большое количество ранних текстов Пастернака, богато инструментован, его подробно описал Вячеслав Всеволодович Иванов [Иванов 2011], поэтому мы на нем не будем подробно останавливаться. Заметим лишь, что, несмотря на обилие звуковых образов в Определении поэзии, определение поэзии в конце стихотворения семантически приходит в качестве итога к глухоте: „Площе досок в воде - духота. / Небосвод завалился ольхою, / Этим звездам к лицу б хохотать, / Ан вселенная - место глухое".

Вернемся к рассматриваемому отрывку. Во второй строфе ряд перечислений продолжается: „Ты - душная, как май, Ямская...” , и в этой строке появляется как бы звуковое зеркало „душнаЯ кАК МАЙ ЯМсКАЯ”. Чумаков говорил об инверсивной звуковой форме во второй строфе, причем рассматривал 6 и 7 стихи как единство: „Повторяющиеся консонанты перевернуты в шестой и седьмой строчках «дш» и «шд», а в шестой строке «май» - «ям»: рядом - две зеркальных инверсии" [Чумаков 2017: 17]. Звуки топонима "Ямская" как будто повторяют в обратном порядке предшествующие в словах „...я как май” - ряд перечислений обрывается, и вместо последующих „определений” появляется динамическое развитие образа:

Ты - душная, как май, Ямская,

Шевардина ночной редут,

Где тучи стоны испускают

И врозь по роспуске идут.

Вдохновение и творчество сравнивается с оборонным укреплением, только что оставленным после долгого сражения (имеется в виду бой накануне Бородинского сражения близ села Шевардино). В этом сравнении есть намек на стремление к поражению [см. Жолковский 2011: 92-116], готовность сдаться, но сдаться вдохновению, то есть такой силе, которой не может противиться поэт. Военные ассоциации в этой войне также напоминают о стихотворении Пей и пиши, непрерывным патру- 
лем..., идущем перед Поэзией в книге Темы и вариации. В нем также есть намек на реалии военного времени, только уже относящиеся не к Отечественной войне 1812 года, а к Первой мировой войне: „Глуби Мазурских озер не разуют / В сон погруженных горнистов Самсонова".

Кроме того, тема военных действий порождает тему смертельной опасности, и это связано с темой творчества, поскольку творчество всегда нечто на грани между жизнью и смертью, нечто, что расположено за пределами обычной жизни, а поэт - человек, выходящий за эти рамки или раздвигающий их. Отметим, что в стихотворении внимание переключается на тучи, которые как будто заменяют солдат, покидающих оставленное укрепление: „Где тучи стоны испускают / И врозь по роспуске идут". Кроме того здесь продолжается мотив железной дороги, начатый в первой строфе сравнением „Ты - лето с местом в третьем классе", которую мы разберем далее. Сейчас же отметим, что, по замечанию Григория Амелина и Валентины Мордерер, образ железной дороги всегда связан с опасностью и мортальностью: „Поезд всегда сокрушителен, катастрофичен, даже тогда, когда ничто, казалось бы, не угрожает. Катастрофа - его постоянная фигура умолчания" [Амелин, Мордерер 2009: 128]. То есть намек на образ железной дороги („И в рельсовом витье двояся [...] Ползут с вокзалов восвояси") продолжает тему смертельной опасности, связанной с вдохновением и творчеством.

После того, как ряд перечислений обрывается в стихотворении появляются глаголы: „тучи стоны испускают / И врозь по роспуске идут”; „И в рельсовом витье двояся, [...] Ползут... оторопев”; „Отростки ливня грязнут в гроздьях / И долго, долго, до зари / Кропают с кровель свой акростих, / Пуская в рифму пузыри". Но самую сильную позицию - слово, завершающее стихотворение, - получает глагол в повелительном наклонении: „Поэзия, когда под краном / Пустой, как цинк ведра, трюизм, / То и тогда струя сохранна, / Тетрадь подставлена, - струись!".

Все стихотворение оказывается развернутым обращением-восклицанием, складывающимся из первого и последнего слов: „Поэзия, струись!". То есть в стихотворении Поэзия отсутствует медитативность, которая была в тексте из Сестры моей жизни. В Поэзии „определение” превращается в эмоциональный призыв к вдохновению, в констатацию его безграничности и безудержности, и этот эффект достигается через отсутствующее в Определении поэзии личностное обращение к Поэзии как к возлюбленной или Музе, и через отличную от стихотворения из Сeстры моей жизни динамическую наполненность глагольных форм.

Динамически рассматриваемые тексты также отличаются, и это проявляется и на уровне ритмической организации текста. В Определении поэзии, как и в других „определениях", - анапест, причем без 
ритмических „сбоев”, хотя Михаил Гаспаров отмечает, что в этом стихотворении используется чередование рифмы, „обратное тому, что было обычно" [см. Гаспаров, Подгаецкая 2008: 145]. То есть в нем сочетаются мужские рифмы с женскими, а не наоборот, что также вносит изменение в ритмический уровень текста. Поэзия ритмически построена более прихотливо. Размер стихотворения - хорей, но в нем почти в каждой строке встречаются пиррихии, часть строк имеют только два ударения, таким образом, в этом тексте появляются пэоны - четырехдольные стопы с одним ударным иктом [см. Квятковский 2008] либо, по определению Андрея Белого, - сочетание ямба или хорея с пиррихием [Белый 2010].

Приведем для примера ритмическую схему третьей строфы стихотворения („И в рельсовом витье двояся, - / Предместье, а не перепев - / Ползут с вокзалов восвояси /Не с песней, а оторопев"):

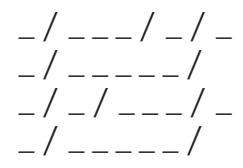

В этой строфе в первой и третьей строках появляется четвертый пэон - четырехдольная стопа с ударением на последнем слоге, а вторая и четвертая строки строятся из сочетания второго и четвертого пэонов. Такое количество пиррихиев создает ощущение „разговорности”, отхода от „ограничивающих метрических требований поэзии” и даже "упрощения" поэтического языка (а „неслыханная простота" - это то, что Пастернак провозгласит своей целью в произведениях после 1930го года).

На их фоне выделяют строки, в которых присутствуют все метрические ударения: „Ты - лето с местом в третьем классе”; „Отростки ливня грязнут в гроздьях"; „Кропают с кровель свой акростих"; „Пустой, как цинк ведра, трюизм". Остановимся подробнее на анализе этих строк.

Семантически строка „Ты - лето с местом в третьем классе” ассоциируется с темами книги Сестра моя - жизнь, наполненной железнодорожными ассоциациями, поскольку роман Бориса Пастернака с Еленой Виноград сопровождался частыми поездками поэта к возлюбленной на поезде. „Лето с местом в третьем классе” - намек на летние поездки в вагонах третьего класса, а ритмический акцент этой строки выделяет ее среди других „определений поэзии”. Кроме того, приведенная строка выделяется и на звуковом уровне: первая строфа наполнена ассонансными повторами: 
ПоЭзия, я буду клясться

Тобой, и кончу, прохрипЕв:

Ты не осАнка сладкоглАсца,

Ты - лЕто с мЕстом в трЕтьем клАссе,

Ты - пригород, а не припЕв.

Здесь в окружении ударных [а] „осанка сладкогласца”, с одной стороны, и „класса” , с другой - звучит троекратное ударное [э] / [е], которое поддерживается во второй и пятой строке в словах „прохрипЕв” и „припЕв", усиленных тем, что эти слова составляют рифму, а также в ключевом слове всего стихотворения „поЭзия" в самом начале стихотворения. Чумаков называл тему звука [е] „своего рода доминантой вокализмов”, отмечая также, что „в одиннадцатом стихе варьируется звуковой повтор пятого стиха: „Предместье, а не перепев”... три [е], затем одна [а], и далее еще три [e] „не-пе-ре-пе-в”, всего семь [е] (с редукциями, но тем не менее)" [Чумаков 2017: 17].

Здесь появляется важная, на наш взгляд, перекличка с книгой Сестра моя - жизнъ. Мы уже упоминали о том, что эта книга и отчасти изданные вслед за ней Темы и вариации были вдохновлены романом с Еленой Виноград. В рифмовке на [е] [Бройтман 2007: 324] и в слове „вселенная” [Долинин 2006] исследователи увидели отсылку к имени возлюбленной Пастернака - „Елена”. Возможно, акцентированные ассонансные повторы звуков [е] и [а] в стихотворении Поэзия также отсылают к тому же аннаграмматически зашифрованному имени.

Отметим также, что рассматриваемая строка сверхнормативна: строфа состоит не из четырех, а из пяти строк с рифмовкой аБааБ. Стихотворение начинается с пятистрочной строфы, поэтому акцент на „лишней” строке оказывается стертым, но далее в тексте идут традиционные четверостишья и ретроспективно ощущается нетипичность первой строфы.

Строфа со строками „Отростки ливня грязнут в гроздьях” и „Кропает с кровель свой акростих" становится своеобразным центром стихотворения, поскольку в ней сосредотачивается один из ключевых образов, характерных для Бориса Пастернака - связь поэзии с водной стихией, причем со стихией часто бурной: дождем или ливнем. Этот образ поддерживается и на звуковом уровне. Аллитерации „тр-гр-знгр-зд” в „Отростки ливня грязнут в гроздьях" и троекратный повтор звукосочетания [кр], поддерживаемый ассонансом ударного [о], в строке „Кропает с кровель свой акростих” как будто имитирует звучание внезапно хлынувшего ливня и предваряет сравнение, которое возникает в следующей строфе: „Поэзия, когда под краном / Пустой, как цинк ведра, трюизм, / То и тогда струя сохранна, / Тетрадь подставлена, струись!". 
Следует оговорить, что мы согласны с отсутствием здесь звукописи как приема: „В стихотворении Поэзия нет никакой звукописи, никакого звукоподражания, слова и фразы идут одна за другой согласно внутреннему замыслу, чувству поэта, согласно правилам его лирического потока" [Чумаков 2017: 15]. Отметим только, что о подобном эффекте в стихотворениях Пастернака говорил еще Тынянов:

Слово смешалось с ливнем... стих переплелся с окружающим ландшафтом, переплелся в смешанных между собой звуками образах. Здесь почти „бессмысленная звукоречь" ... И в результате этой алхимической стиховой операции ливень начинает быть стихом... [Тынянов 1977: 183].

„Пустой, как цинк ведра, трюизм” - еще один стих, в котором есть ударения на всех иктах четырехстопного ямба. Ритм здесь также поддерживает образ капель дождя, ударяющих в ведро, но также как будто подготавливает к последней строке с возгласом „струись!”, который, как мы говорили выше, превращается в квинтэссенцию всего текста.

Так, мы видим, что в стихотворении Поэзия отразились темы и мотивы, появлявшиеся в книге Сестра моя - жизнъ. В нем поэт также использовал схожие приемы, создающие асемантический уровень ткани художественного текста. И хотя в стихотворении предпринята попытка дать „определение” поэзии, внутренняя динамика текста заметно отличается от текста Определение поэзии из книги Сестра моя - жизнъ. Сопоставление этих поэтических текстов позволяет увидеть изменения, которым подвергался литературный стиль Бориса Пастернака в 1920-х годах.

\section{Библиография}

Абрамова К. 2011. Микроцикл «Болезнь» 6 контексте книги Б. Пастернака «Темы и вариации», [в:] Русская митература: пексты и контексты, М. Łukaszewicz, J. Cehner, J. Piotrowska (ред.), Варшава.

Абрамова К. 2012. Цикл «Разрыв» как кульминация книги стихов Б. Пастернака «Темы и вариации», „Вестник Удмуртского университета”, № 4.

Альфонсов В. 1990. Поэзия Бориса Пастернака, Ленинград: Советский писатель.

Амелин Г., Мордерер В. 2009. Письма о русской поэзии, Москва: Знак.

Баевский В. С. 2011. Пушкинско-пастернаковская культурная парадигма, Москва: Языки славянской культуры.

Баевский В. С., Романова И. В. 2008. Поэтика книги Б. Пастернака «Сестра моя - жизнъ», „Известия РАН”, т. 67, № 5.

Белый Андрей. 2010. Собрание сочинений. Символизм. Книга статей, В. М. Пискунова (общ. ред.), Москва: Культурная революция; Республика.

Бройтман С. Н. 2006. Из монографии С.Н. Бройтмана "Поэтика книги Бориса Пастернака «Сестра моя - жизнъ»”, „Новый филологический вестник” № 1 (2). 
Бройтман С. Н. 2007. Поэтика книги Бориса Пастернака „Сестра моя - жизнь”, Москва: Прогресс-Традиция.

Брюсов В. Я. 1922. Вчера, сегодня и завтра русской поэзии, „Печать и революция”, № 7, электронный ресурс: http://az.lib.ru/b/brjusow_w_j/text_1922_vchera_ segodnya_zavtra_russkoy_poezii.shtml (доступ 7.11.2017).

Гаспаров Б. М. 2013. Борис Пастернак: по ту сторону поэтики (Философия. Музыка. Быт), Москва: Новое литературное обозрение.

Гаспаров М. Л., Подгаецкая И. Ю. 2008. „Сестра моя - жизнь” Бориса Пастернака. Сверка понимания, Москва: РГГУ.

Гаспаров М. Л., Поливанов К. М. 2005. „Близнеи в тучах” Бориса Пастернака: опыт комментария, Москва: РГГУ.

Горелик Л. Л. 2011. „Миф о творчестве” в прозе и стихах Бориса Пастернака, Москва: РГГУ.

Долинин А. 2006. Шекспировские алюзии в ранней поэзии Пастернака („,Уроки английского"). Доклад на IV-х Эткиндовских чтениях, Санкт-Петербург.

Жолковский А. К. 2014. Поэтика за чайным столом и другие разборы, Москва: Новое литературное обозрение.

Жолковский А. К. 2011. Поэтика Пастернака: инварианты, структуры, интертексты, Москва: Новое литературное обозрение.

Иванов Вяч. Вс. 2011. Структура трех стихотворений-„определений" в изикле «Занятье философией» из книги Пастернака «Сестра моя жизнъ», [в:] А. Л. Оборина, Е.В. Пастернак (ред.), Пастернаковский сборник: статьи и публикации I, Москва: РГГУ.

Квятковский А. П. 2008. Ритмология, Санкт-Петербург: ИНАПРЕСС, Издательство Дмитрий Буланин.

Мальцева О. А. 2015. Амбивалентная символика в начальных стихотворениях ицикла Б. Пастернака „Нескучный сад”, „Вестник Московского университета”, № 6.

Пастернак Б. 1927. Две книги. Стихи, Москва, Ленинград: Государственное издательство.

Пастернак Б. 2003. Полное собрание сочинений в 11 m, т. I: Стихотворения и поэмы 19121931, сост. и коммент. Е. Б. Пастернак и Е. В. Пастернак, Москва: СЛОВО/SLOVO.

Пастернак Е. (сост.) 2012. Б. Л. Пастернак: pro et contra, антология, т. 1, Санкт-Петербург: Изд-во РГХА.

Пастернак Е. Б. 1997. Борис Пастернак: Биография, Москва: Цитадель.

Сергеева-Клятис А. Ю. 2013. Пастернак В 1922 году: к вопросу о восприятии современниками творчества Пастернака, „Вестник русской христианской гуманитарной академии", т. 14, № 4 .

Тынянов Ю. Н. 1997. Поэтика. История литературы. Кино, Москва: Наука.

Чумаков Ю. Н. 2017. Асемантическая сторона текста: Борис Пастернак. „Поэзия”, „Критика и семиотика", № 1. 
